
UNDER CONTRACT DE-AC02-76CH03073

PPPL-3611

PPPL-3611

UC-70

Initial Studies of Core and Edge Transport of NSTX Plasmas

by

E.J. Synakowski, M.G. Bell, C.E. Bush, C. Bourdelle, D. Darrow,

W. Dorland, A. Ejiri, E.D. Fredrickson, D.A. Gates, S.M. Kaye,

S. Kubota, H.W. Kugel, B.P. LeBlanc, R. Maingi, R.J. Maqueda,

J.E. Menard, D. Mueller, A. Rosenberg, S.A. Sabbagh, D. Stutman,

G. Taylor, D.W. Johnson, R. Kaita, M. Ono, F. Paoletti, W. Peebles, Y-K.M. Peng, A.L. Roquemore, C.H. Skinner, V.A. Soukhanovskii, and the NSTX Research Team

September 2001
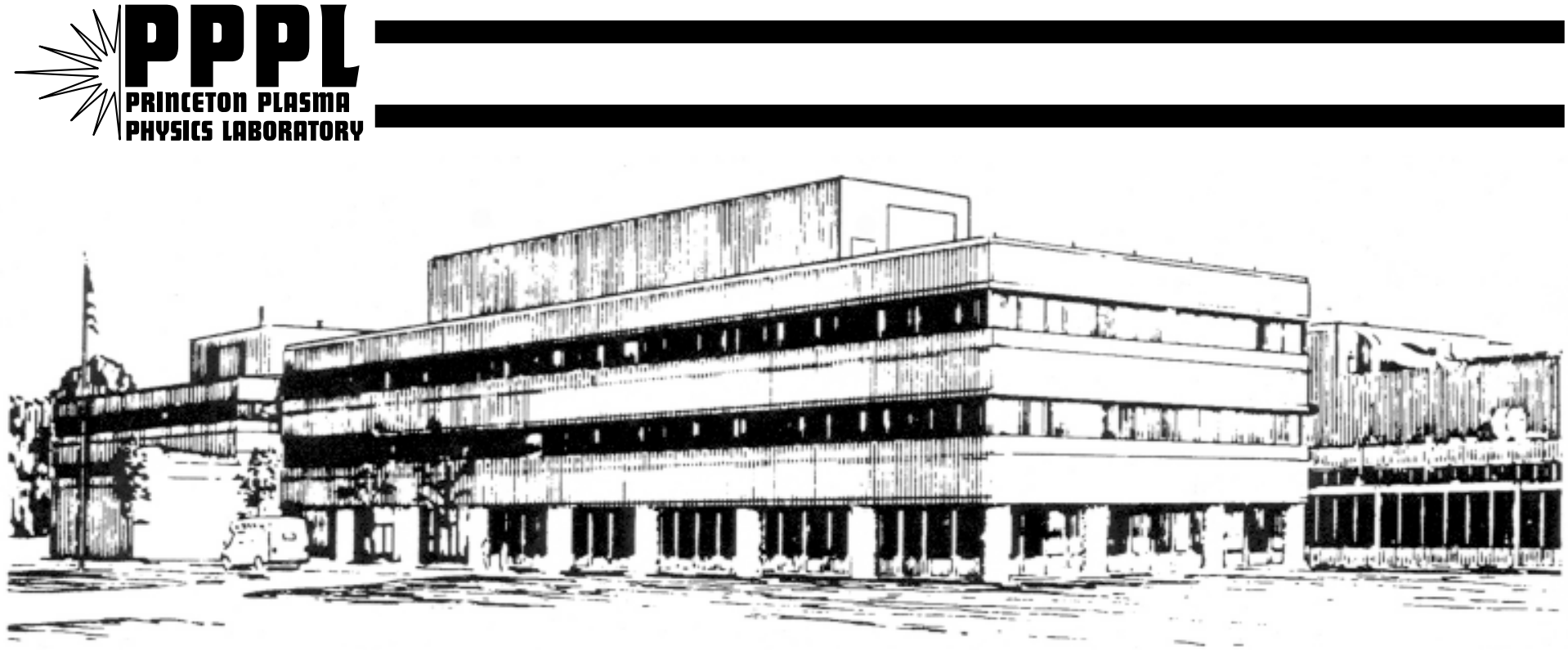

PRINCETON PLASMA PHYSICS LABORATORY PRINCETON UNIVERSITY, PRINCETON, NEW JERSEY 


\section{PPPL Reports Disclaimer}

This report was prepared as an account of work sponsored by an agency of the United States Government. Neither the United States Government nor any agency thereof, nor any of their employees, makes any warranty, express or implied, or assumes any legal liability or responsibility for the accuracy, completeness, or usefulness of any information, apparatus, product, or process disclosed, or represents that its use would not infringe privately owned rights. Reference herein to any specific commercial product, process, or service by trade name, trademark, manufacturer, or otherwise, does not necessarily constitute or imply its endorsement, recommendation, or favoring by the United States Government or any agency thereof. The views and opinions of authors expressed herein do not necessarily state or reflect those of the United States Government or any agency thereof.

\section{Availability}

This report is posted on the U.S. Department of Energy's Princeton Plasma Physics Laboratory Publications and Reports web site in Calendar Year 2001. The home page for PPPL Reports and Publications is: http://www.pppl.gov/pub_report/

DOE and DOE Contractors can obtain copies of this report from:

U.S. Department of Energy

Office of Scientific and Technical Information

DOE Technical Information Services (DTIS)

P.O. Box 62

Oak Ridge, TN 37831

Telephone: (865) 576-8401

Fax: (865) 576-5728

Email: reports@adonis.osti.gov

This report is available to the general public from:

National Technical Information Service

U.S. Department of Commerce

5285 Port Royal Road

Springfield, VA 22161

Telephone: 1-800-553-6847 or

(703) 605-6000

Fax: (703) 321-8547

Internet: http://www.ntis.gov/ordering.htm 


\title{
Initial Studies of Core and Edge Transport of NSTX plasmas
}

\author{
E.J. Synakowski ${ }^{\mathrm{a}}$, M.G. Bell ${ }^{\mathrm{a}}$, R.E. Bell ${ }^{\mathrm{a}}$, C.E. Bush ${ }^{\mathrm{b}}$, C. Bourdelle ${ }^{\mathrm{a}}$, D. Darrow ${ }^{\mathrm{a}}$, \\ W. Dorland ${ }^{\text {c }}$, A. Ejiri ${ }^{\text {, }}$, E.D. Fredrickson ${ }^{\text {a }}$, D.A. Gates ${ }^{\text {a }}$, S.M. Kaye ${ }^{\text {a }}$, S. Kubota ${ }^{\mathrm{e}}$, \\ H.W. Kugel ${ }^{a}$, B.P. LeBlanc ${ }^{a}$, R. Maingi ${ }^{b}$, R.J. Maqueda ${ }^{\text {g }}$, J.E. Menard ${ }^{\text {a }}$, \\ D. Mueller ${ }^{\mathrm{a}}$, A. Rosenberg ${ }^{\mathrm{a}}$, S.A. Sabbagh ${ }^{\mathrm{f}}$, D. Stutman ${ }^{\mathrm{h}}$, G. Taylor ${ }^{\mathrm{a}}$, \\ D.W. Johnson ${ }^{\text {a }}$, R. Kaita ${ }^{a}$, M. Ono ${ }^{\text {a }}$, F. Paolettif ${ }^{\mathrm{f}}$, W. Peebles ${ }^{\mathrm{e}}$, Y-K.M. Peng ${ }^{\mathrm{b}}$, \\ A.L. Roquemore ${ }^{a}$, C.H. Skinner ${ }^{\mathrm{a}}$, V.A. Soukhanovskii ${ }^{\mathrm{a}}$, and the NSTX Research \\ Team
}

\footnotetext{
${ }^{a}$ Princeton Plasma Physics Laboratory, PO Box 451, Princeton, NJ, 08543 USA

${ }^{\mathrm{b}}$ Oak Ridge National Laboratory, Oak Ridge TN, 37831 USA

${ }^{\mathrm{c}}$ Univeristy of Maryland, College Park, MD, 20742 USA

${ }^{\mathrm{d}}$ University of Tokyo, Tokyo 113-0033 Japan

e University of California at Los Angeles, Los Angeles, CA 90095 USA

${ }^{f}$ Columbia University, New York, NY, 10027 USA

${ }^{\mathrm{g}}$ Los Alamos National Laboratory, Los Alamos, NM, 87545 USA

h Johns Hopkins University, Baltimore, MD, 21218 USA
}

\begin{abstract}
Rapidly developing diagnostic, operational, and analysis capability is enabling the first detailed local physics studies to begin in high beta plasmas of the National Spherical Torus Experiment (NSTX).

These studies are motivated in part by energy confinement times in neutral-beam-heated discharges that are favorable with respect to predictions from the ITER-89P scaling expression. Analysis of heat fluxes based on profile measurements with NBI suggest that the ion thermal transport may be exceptionally low, and that electron thermal transport is the dominant loss channel. This analysis motivates studies of possible sources of ion heating not presently accounted for by classical collisional processes. Gyrokinetic microstability studies indicate that long wavelength turbulence with $\mathrm{k}_{\theta} \rho_{\mathrm{i}} \sim 0.1-1$ may be suppressed in these plasmas, while modes with $\mathrm{k}_{\theta} \rho_{\mathrm{I}} \sim 50$ may be robust. High harmonic fast wave (HHFW) heating efficiently heats electrons on NSTX, and studies have begun using it to to assess transport in the electron channel. Regarding edge transport, H-mode transitions occur with either NBI or HHFW heating. The power required for L- to $\mathrm{H}$-mode transitions far exceeds that expected from empirical ELM-free $\mathrm{H}$ mode scaling laws derived from moderate aspect ratio devices. Finally, initial fluctuation measurements made with two techniques are permitting the first characterizations of edge turbulence.
\end{abstract}

\section{Introduction}

The spherical torus (ST) magnetic geometry and that of the conventional aspect ratio tokamak may result in testable differences in transport and turbulence dynamics. For example, in the ST, 
the low magnetic field, strong magnetic field gradient, and the possibility of high beta all combine to suggest that long wavelength turbulence suppression by both ExB flow shear [1,2] and geometrical effects owing to favorable field line curvature [3] may be a pervasive feature of high beta ST plasmas. Changes in the ordering of characteristic velocities in the ST as compared to the tokamak also may influence heating and turbulence. For neutral beam heating, a typical ordering in conventional aspect ratio tokamaks is $\mathrm{V}_{\text {Alfven }}>\mathrm{V}_{\mathrm{b}}>\mathrm{V}_{\mathrm{th}}$, where $\mathrm{V}_{\text {Alfven }}$ is the characteristic Alfven speed, $\mathrm{V}_{\mathrm{b}}$ is the velocity of a newly ionized beam ion, and $\mathrm{V}_{\text {th }}$ is the thermal velocity of a working ion. In the ST, lower magnetic field and high beta lead to a different ordering, namely, $\mathrm{V}_{\mathrm{b}}>\mathrm{V}_{\text {Alfven }} \sim \mathrm{V}_{\text {th }}$. One possible consequence is that the interactions between MHD and acoustic waves may be of more fundamental importance in the ST than in tokamaks at moderate A. Regarding the plasma edge, the magnetic shear strength is larger in the ST. Also, there is a larger ratio in the inboard vs. outboard magnetic field strength of the ST as compared to moderate aspect ratio devices. If poloidal damping plays a role in determining $\mathrm{H}$ mode power thresholds, this may result in a difference in $\mathrm{H}$ mode access requirements between the two device types that can help distinguish between various bifurcation theories. In addition, owing to the large differences in the ion Larmor radius at the plasma between the ST and the moderate aspect ratio tokamak, tests of the physics that determines the pedestal width and height in the $\mathrm{H}$ mode may be afforded by a comparison of these two configurations.

In this work, results from initial transport characterization of both the core and the edge of NSTX [4,5] are outlined. An underlying theme guiding this research in the long term is characterization with the identification of the sorts of testable differences mentioned above. Described here are observed global confinement trends and comparisons to an empirical scaling expression derived from the moderate aspect ratio database. Core confinement characteristics with neutral beam heating are described, including a description of a preliminary assessment of power flows in the ion and electron thermal channels. A brief description of the first gyrokinetic microinstability analyses is given. Results from core high harmonic fast wave heating are described, with emphasis on its potential as a probe for electron thermal transport studies already deemed important at moderate aspect ratio. For the plasma edge, a description of $\mathrm{H}$ mode access requirements is provided. Features of the density profile evolution is described, as are some features of turbulence characteristics. 
Synakowski et al.

\section{Core transport characteristics}

A. Neutral Beam Heating - Assessment of global scaling characteristics in plasmas with neutral beam injection (NBI) reveal favorable trends in the energy confinement time when compared to the ITER-89P empirical scaling law (Fig. 1). All but two of the data points in the figure exhibited L-Mode behavior with respect to the plasma edge. The data were evaluated at times of peak stored energy and during periods of MHD quiescence, The results underscore the necessity of understanding of this favorable scaling based on local physics diagnosis and analysis.

Profile measurements of electron temperature $T_{e}$, electron density $n_{e}$, impurity ion temperature $T_{i}$, impurity toroidal rotation velocity $V_{\phi}$, and assessments of the plasma effective charge are all enabling power balance analyses of NSTX plasmas to take place. Profiles measured for a plasma with toroidal beta $\left(\beta_{\mathrm{T}}\right)$ of about $20 \%$, as determined by magnetics analysis using the EFIT code [6], are shown in Figure 2. The neutral beam injection is unidirectional and parallel to the plasma current (co-injection). The $T_{e}$ and $n_{e}$ profiles are measured with a high throughput, multitimepoint Thomson scattering system [7], and the $T_{i}$ and $V_{\phi}$ profiles are measured using charge exchange recombination spectroscopy (CHERS). Characteristics shown are typical of many results from other high beta NSTX plasmas, including a $T_{i}$ profile that is broader than the $T_{e}$ profile, and carbon toroidal rotation velocities that rival the local ion thermal speed. The edge rotation velocity of several tens of $\mathrm{km} / \mathrm{s}$ are not unusual, but are not seen in all discharges. The distortions in the rotation profile away from a monotonic shape, such as that shown in the figure, have been correlated with core MHD activity [8].

In neutral beam heated plasmas, analysis of heating and power flows point to puzzles. Analysis with the TRANSP code of the classical heating of electrons and thermal ions through collisions with the fast beam ions suggest that the largest fraction of the fast ion energy ought to be transferred to the electrons, with the remainder transferred to the thermal ions. However, the power transfer due to thermal ion-electron coupling alone is calculated to easily exceeds the fast ion energy coupled to the thermal ions directly. The possibility that another source of heating is providing energy to the ions is thus being investigated. Avenues being explored include the role of collisional Alfven waves, induced by the beam ions which then stochastically heat the thermal ions through nonlinear wave-particle interactions [9]. The work is an extension of nonlinear theory developed to explain the anomalously high ion temperatures measured in solar coronal loops [10]. Also, the role of small aspect ratio effects on collisional coupling are being 
investigated. The rapid rotation speeds is also motivating investigation of the role of centrifugal heating. Finally, a series of experiments aimed at identifying diagnostic errors have been executed. Thus far, no systematic diagnostic errors has been identified that can account for these analysis results.

The evidence at present, then, is that the ion thermal transport is at the least subdominant in these plasmas, and the electron thermal transport is the dominant thermal loss channel. Even if the deficit in the ion power flows is accounted for by a yet unknown source of ion heating, and this mechanism succeeds in transferring all of the fast ion energy to the thermal ions, one is still forced to conclude that nearly all of that energy is then transferred via collisions from the thermal ions to the electrons rather than being exhausted by ion thermal conduction.

Theory analysis is underway to explore this. Microinstability analysis using the GS2 gyrokinetic code [11] suggests that long wavelength ion thermal gradient (ITG) and trapped electron (TEM) modes, with $\mathrm{k}_{\theta} \rho_{\mathrm{i}} \sim 0.1-1$, where $\mathrm{k}_{\theta}$ is the poloidal wavenumber and $\mathrm{p}_{\mathrm{i}}$ is the thermal ion gyroradius, are stable or have low instability drives relative to the ExB shear (Fig. 3(a)). Shorter wavelength electron thermal gradient (ETG) modes, with $\mathrm{k}_{\theta} \rho_{\mathrm{i}} \sim 30-50$, have higher growth rates [12]. Preliminary nonlinear analysis is allowing the first predictions of electron thermal fluxes generated by these short wavelength modes and suggest that ETG activity may account for a significant fraction of the heat flux in the core. Clearly, these theoretical analyses demand detailed measurements of core turbulence at low and high wavenumber for their confirmation.

B. High Harmonic Fast Wave Heating - Waves launched at a high harmonic of the ion fundamental cyclotron frequency have proven to be effective in heating electrons on NSTX $[13,14]$, as anticipated in Ref. [15]. Analysis above suggests that the electron thermal transport is the dominant loss channel. It is revealing, then, to compare energy confinement times for NBIheated plasmas, where ion heating is demonstrated, and HHFW-heated plasmas, where nearly all of the power is expected to be coupled to the electrons. For example, for a $4 \mathrm{kG}, 1 \mathrm{MA}$ plasma with 1.5 MW of NBI, $\tau_{\mathrm{E}}=70 \mathrm{~ms}$. However, for a $3 \mathrm{kG}, 800 \mathrm{kA}$ plasma heated with $1.85 \mathrm{MW}$ of HHFW and of nearly the same line-integrated electron density, $\tau_{\mathrm{E}}=25 \mathrm{~ms}$. By contrast, the ratio of HHFW- to NBI-heated plasma confinement times for these discharges predicted by the ITER89-P empirical scaling relation is 0.85 . Since nearly all of the heating is expected to be 
Synakowski et al.

coupled to the electrons in the HHFW case, this comparison of global parameters is consistent with the suggestion from local analysis that electron thermal conduction is considerably greater than ion thermal conduction in these plasmas.

Studies have begun on NSTX using HHFW to explore the dependence of local transport on $\mathrm{T}_{\mathrm{e}}$ and its gradient. Recent heating results using HHFW reveal effective central heating and the generation of peaked $T_{e}$ profiles (Fig. 4(a)). Separation of transport effects and heat source effects in generating these steep temperature gradients requires a detailed validation of power deposition profiles from HHFW. Power balance analysis of discharges such as those shown in Fig. 4 has begun. A preliminary assessment of the electron thermal conductivity, made using ray tracing calculations of the HHFW power deposition, suggests that $\chi_{\mathrm{e}}$ indeed falls in the core with increasing $\mathrm{T}_{\mathrm{e}}$. Further studies require detailed confirmation of the deposition profile of the high harmonic fast waves.

A component of a possible explanation for the apparent drop in transport is suggested by microinstability analysis [12] which indicates that the ratio of $T_{i} / T_{e}$ may be an important determining factor in the strength and stability of short wavelength ETG modes. The linear growth rates for the NBI-heated NSTX plasma evaluated in Fig. 3. are shown for one location near the mid-radius (Figure 4). The measured value of $T_{i} / T_{e}$ is 2.7 at the location of the calculation. For this case, long wavelength modes with $\mathrm{k}_{\theta} \rho_{\mathrm{i}} \sim 0.1-1$ are calculated to be stable, while ETG modes with $\mathrm{k}_{\theta} \rho_{\mathrm{i}} \sim 0.10-100$ are expected to be virulent. When $\mathrm{IT}_{\mathrm{e}}$ is reduced while keeping the plasma equilibrium, beta, density profile, and other plasma quantities fixed, the ETG drive falls. A calculation performed with $\mathrm{T}_{\mathrm{i}} / \mathrm{T}_{\mathrm{e}}=0.3$ revealed that the ETG modes can be made stable. This stabilizing trend with reduced $\mathrm{T}_{\mathrm{i}} / \mathrm{T}_{\mathrm{e}}$ is accompanied by increasing instability of the long wavelength modes. This observation that low (high) $\mathrm{T}_{\mathrm{i}} / \mathrm{T}_{\mathrm{e}}$ ratios can stabilize ETG (ITG) turbulence reflects a symmetry in the roles of the temperatures in the turbulence theory. To investigate this in a more controlled fashion, experiments where $T_{i} / T_{e}$ was varied at nearly constant beta by varying the density were recently. These will form the basis of detailed power balance, heat deposition, and microstability analysis.

\section{Edge transport}

Studies in lower single null diverted discharges reveal that the $\mathrm{H}$ mode is a distinct confinement regime on NSTX $[16,17]$ that exhibits the usual signatures of drops in recycling $\mathrm{D}_{\alpha}$ light, rapid 
steepening of edge gradients, ELMing and ELM-free periods, and reductions in edge turbulence activity. The first $\mathrm{H}$ mode plasmas were obtained with neutral beam injection; these results are discussed here. More recently, $\mathrm{H}$ mode plasmas have been generated with HHFW heating as well.

For a given plasma shape, magnetic field, density, and plasma current, a power threshold is often used to characterize access requirements. To determine the power threshold for a given configuration with NBI, the neutral beam voltage was reduced to achieve input power levels below those normally obtainable with a single neutral beam source. For $0.9 \mathrm{MA}$ and a toroidal field of $0.45 \mathrm{~T}$ and a line-averaged density of $1.5 \times 10^{19} \mathrm{~m}^{-3}$, the power threshold was determined to be $840 \mathrm{~kW}$, if ohmic power is ignored. Including the ohmic power yields a threshold value of approximately $2 \mathrm{MW}$. This is to be compared to the value obtained from the empirical scaling relation based on moderate aspect ratio tokamaks of $50 \mathrm{~kW}$ for these conditions. It is interesting to note that, while the required power differs from the scaling prediction, it is similar to that observed in DIII-D, which is comparable in minor radius. The maximum energy confinement time inferred thus far in an $\mathrm{H}$ mode is $120 \mathrm{~ms}$. Upcoming probe measurements of fluctuation characteristics should allow investigation of the speculation [18] that partial cancellation of the Reynolds and Maxwell stress may be responsible for the comparatively high power thresholds observed thus far.

The edge transport characteristics reveal their strongest changes most clearly in the density profile measurements. In the absence of ELMs, and for $30-50 \mathrm{~ms}$ after the transition, pronounced ears in the density profile are observed [Fig. 5]. Similar features have been reported for H modes on MAST [19]. The persistence of this feature is particularly noteworthy in comparison to the slow response of the central electron density after the transition. Quantitative assessment of the local transport in this edge region as compared to the core demands an accurate accounting for the source of particles from the plasma wall; such an assessment based on 2D particle source measurements in the divertor, probe measurements of scrapeoff parameters, and coupled UEDGE and DEGAS2 modelling [20] is underway.

Initial fluctuation measurements have been made in the NSTX boundary, including changes observed across L-H and H-L transitions. Two diagnostic systems have been deployed for these measurements thus far; a reciprocating probe will be deployed in the next series of NSTX experiments. Shown in Fig. 6(a,b) are results from fast camera imaging of neutral helium 
emission excited by electron collisions [21]. The helium is introduced by gas puffing in a sheet near the plasma periphery, and intensity variations are interpreted as fluctuations in the background electron density. The turbulence exhibits sharp reductions in the transition from the $\mathrm{H}$ mode phase as compared to the $\mathrm{L}$ mode. There is a remarkably rapid return of fluctuation levels as the plasma returns to the L mode state: the autocorrelation time for the return to the turbulent state has been measured to be of order $20 \mu \mathrm{s}$. Reflectometry measurements [22] also reveal rapid reductions in the scattered power across an L- to H-mode transition, and rapid increases following the back transition. Measurements of fluctuation correlation lengths with this system are underway. Fluctuation levels have been inferred using quadrature detection in the plasma scrapeoff; the time series of these data reveal substantial increases in turbulent activity in the back transition to the L mode phase in the same discharge described in Fig. 6. To quantify understanding of these turbulence dynamics and the dynamics of the NSTX edge in general, simulations with edge turbulence transport codes, such as BOUT [23], have begun. Using edge density and temperature gradients estimated from Thomson scattering, simulations thus far are consistent with the imaging observations of long filamentary structures in the edge of the NSTX plasma in the L mode phase.

\section{Summary}

Diagnosics, analysis, and operational capability have all advanced to enable the first detailed local studies of high beta, low aspect ratio physics to commence. Compared to moderate aspect ratio, global scaling of confinement is favorable on NSTX with NBI, and power thresholds for the L- to H-mode transition are an order of magnitude higher than suggested for edge $\mathrm{H}$ mode scalings. The study of ion and electron heat fluxes in the core suggest that electron thermal transport may be the dominant thermal loss channel in the core. Two diagnostic systems confirm the rapid changes of turbulence amplitudes across transitions between the L- and H-mode states. Future physics studies, including intermachine comparison experiments being developed with programs such as that at DIII-D, will be directed towards further revealing the new physics uncovered by large changes in aspect ratio and beta.

This research was supported by the U. S. Dept. of Energy under contracts DE-AC02-76CH03073, DE-AC05-00OR22725, W-7405-ENG-36, and grant DE-FG02-99ER54524. 


\section{References}

[1] Stambaugh R D et al. 1996 Proc. $16^{\text {th }}$. Int. Conf. Plasma Physics and Controlled Nuclear Fusion Research (Montreal, Canada) (Vienna: IAEA) Fusion Energy 1996

[2] M. Kotschenreuther et al., Nuclear Fusion 200040677

[3] Rewoldt G et al., Phys. Plasmas 199631667

[4] Kaye S et al., Fusion Technol. 19993616

[5] Peng Y -K, Phys. Plasmas 200081681

[6] Lao L et al Nucl. Fusion 1990301035

[7] Johnson D et al. Rev. Sci. Instru. 199970776

[8] Bell R.E. et al., Proceedings of the $28^{\text {th }}$ EPS Conference on Controlled Fusion and Plasma Physics

[9] Gates D, Gorelenkov N, White R.B., submitted to Phys. Rev. Lett.

[10] Chen L, Lin Z, White R.B., submitted to Phys. Rev. Lett.

[11] Kotschenreuther M et al., Comp. Phys. Comm. 1995881281995.

[12] Bourdelle $\mathrm{C}$ et al., Proceedings of the Second IAEA Technical Committee Meeting on Spherical Tori and the $7^{\text {th }}$ International Spherical Torus Workshop, São José dos Campos, SP, Brazil, 2001

[13] Wilson J R et al., Proceedings of $18^{\text {th }}$ Int. conf. Plasma Physics and Controlled Nulcear Fusion Research (Sorrento, Italy) (Vienna: IAEA), to be published

[14] LeBlanc B, Proceedings of the $14^{\text {th }}$ Topical Conference on Radio Frequency Power in Plasmas, Oxnard, California, 2001

[15] Ono M, Phys Plasmas 199524075

[16] Maingi R et al., submitted to Phys. Rev. Lett.

[17] Bush, C E, these proceedings

[18] Hahm T.S., these proceedings

[19] Sykes, A et al., Phys. Plasmas 200182101

[20] Stotler, D P et al., Contrib.. Plasma Phys. 200040221

[21] Maqueda R.J. et al., Rev. Sci. Instrum. 200172931

[22] Kubota S et al., Rev. Sci. Instrum. 200172348

[23] Xu, X.Q., and Cohen, R.H., Contrib. Plasma Phys.1998 38158 
Synakowski et al.

Figure 1. Measured energy confinement times, inferred from magnetics analysis, versus predictions from the empirical scaling law ITER89-P. Results for neutral beam heated discharges are shown. Confinement times are evaluated in periods absent of MHD, as well as at the time of maximum stored energy.

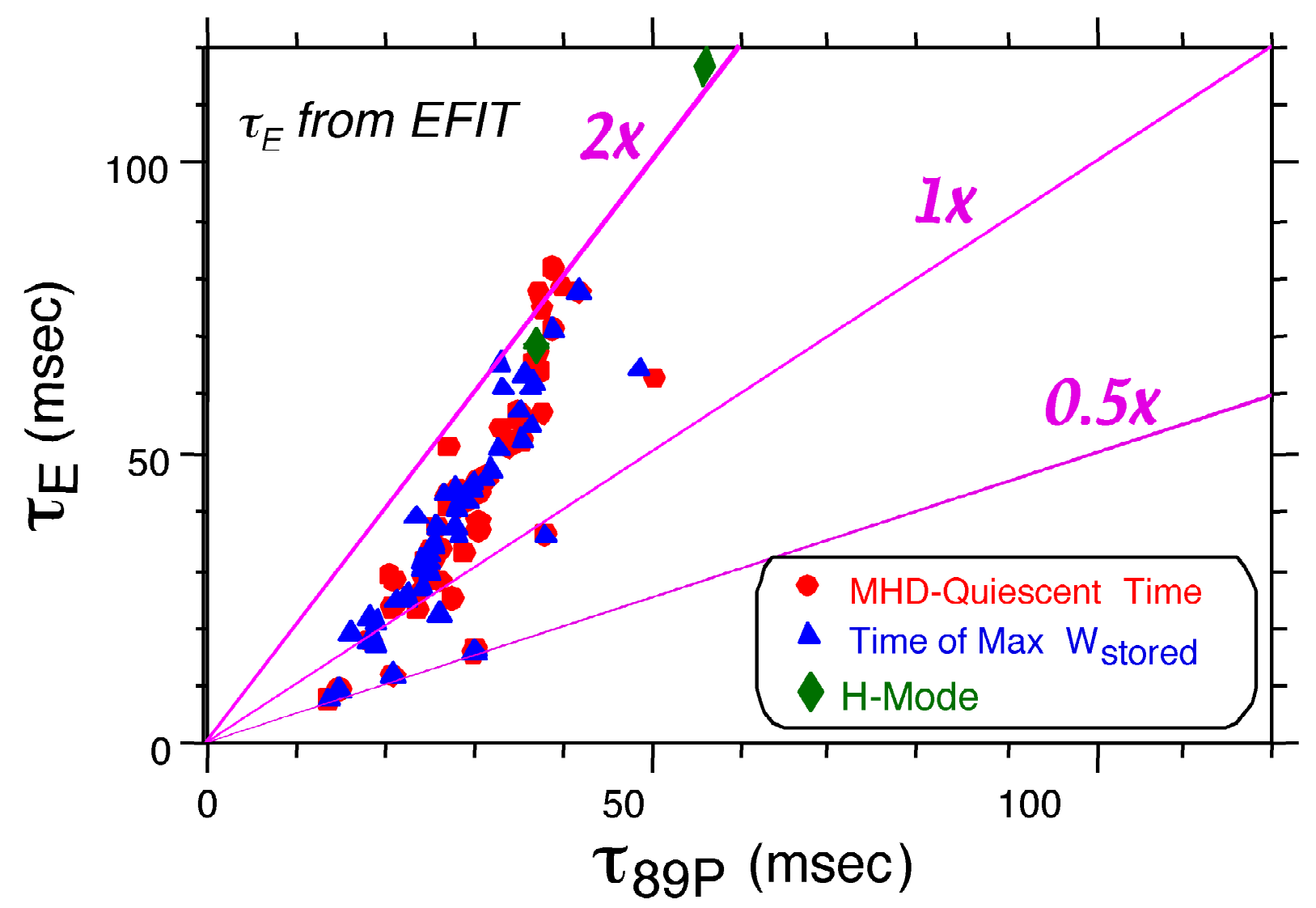


Synakowski et al.

Figure 2. (a). The plasma current, neutral beam heating power, and a Mirnov coil signal. The vertical line shows the time of the Thomson scattering $T_{e}$ and $n_{e}$ measurements, while the broader band shows the integration period of the CHERS measurement. (b). Carbon ion temperature and toroidal rotation and electron temperature profiles at the times indicated in (a). (c). Electron density profile. (d). The q profile, inferred from magnetics measurements using the EFIT code.
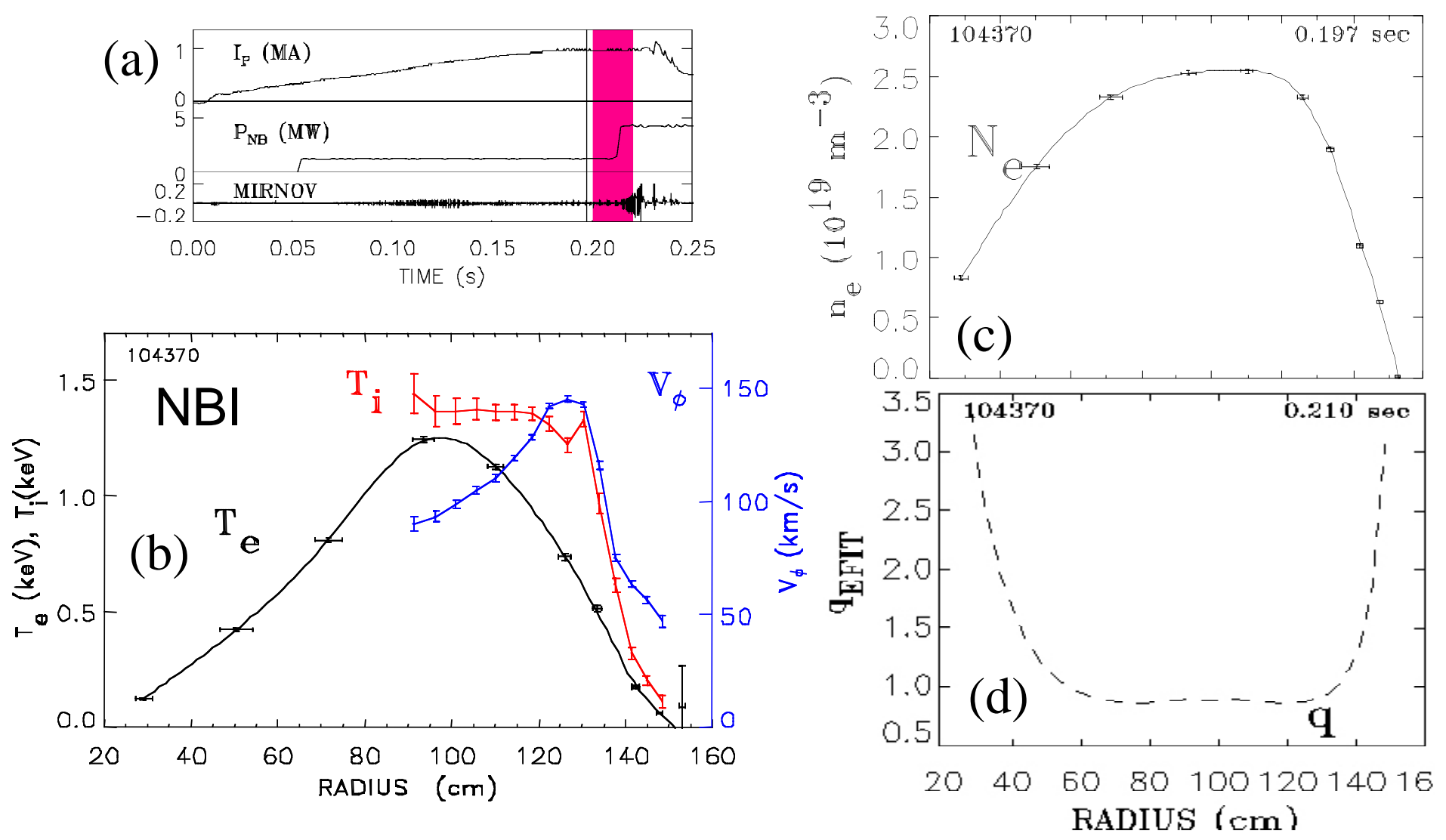
Synakowski et al.

Figure 3. Peak instability growth rates for low and high $\mathrm{k}$ modes for the plasma described in Figure 2. Analysis was performed with the GS2 code.

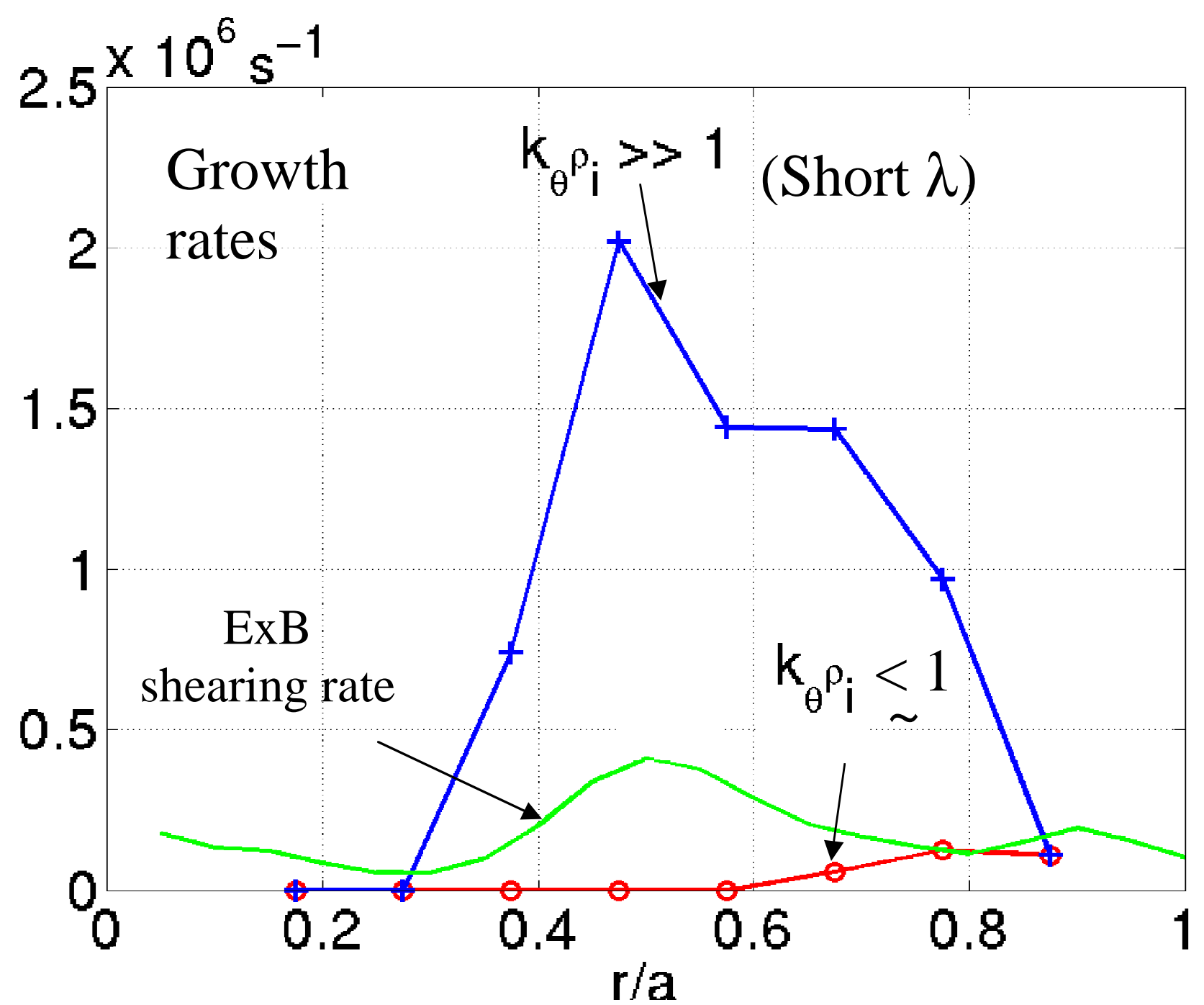


Synakowski et al.

Figure 4. Electron temperature profiles for a plasma with $3.5 \mathrm{MW}$ of HHFW heating.

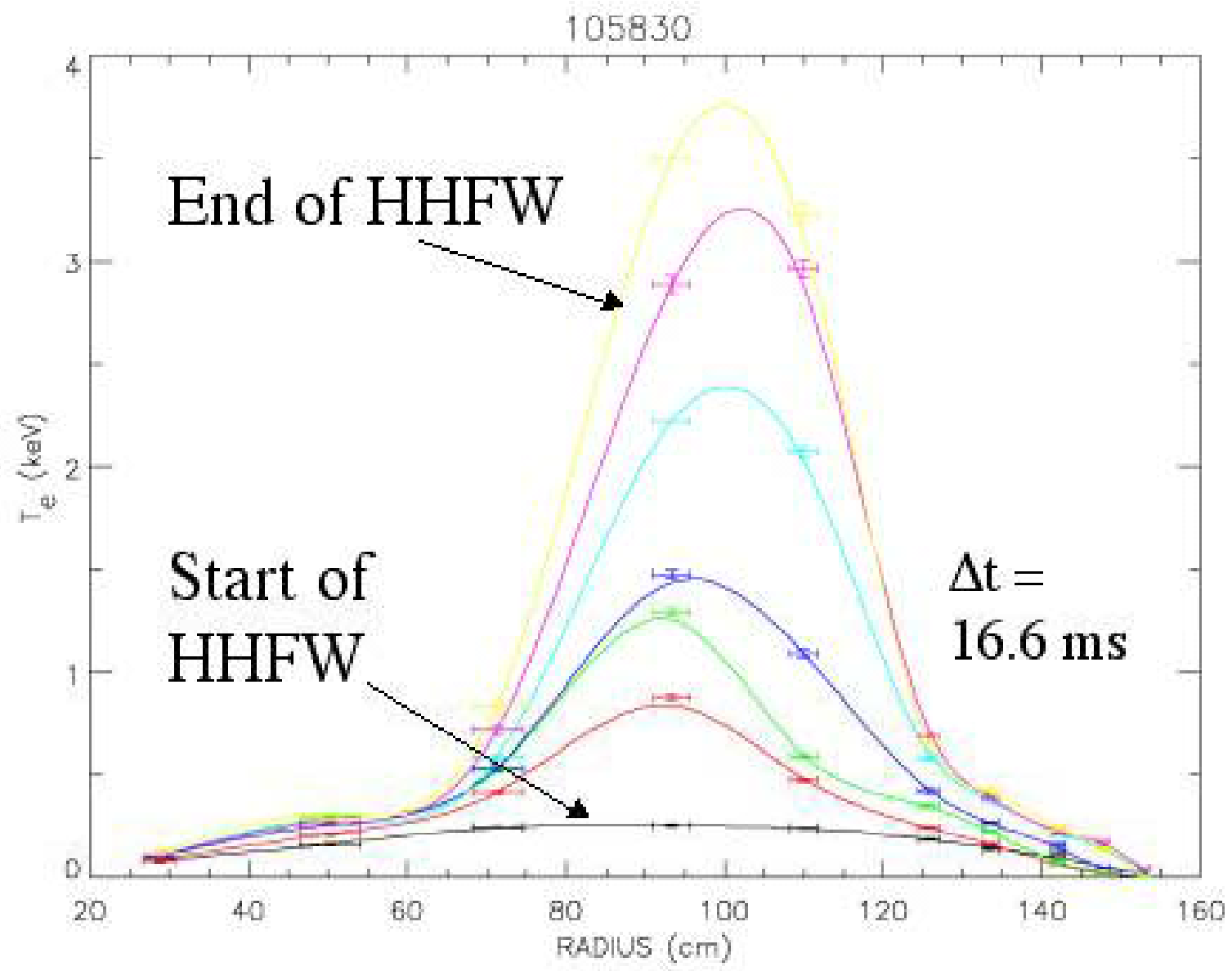


Synakowski et al.

Figure 5. Density profile evolution in an ELM-free, neutral-beam-heated H mode.

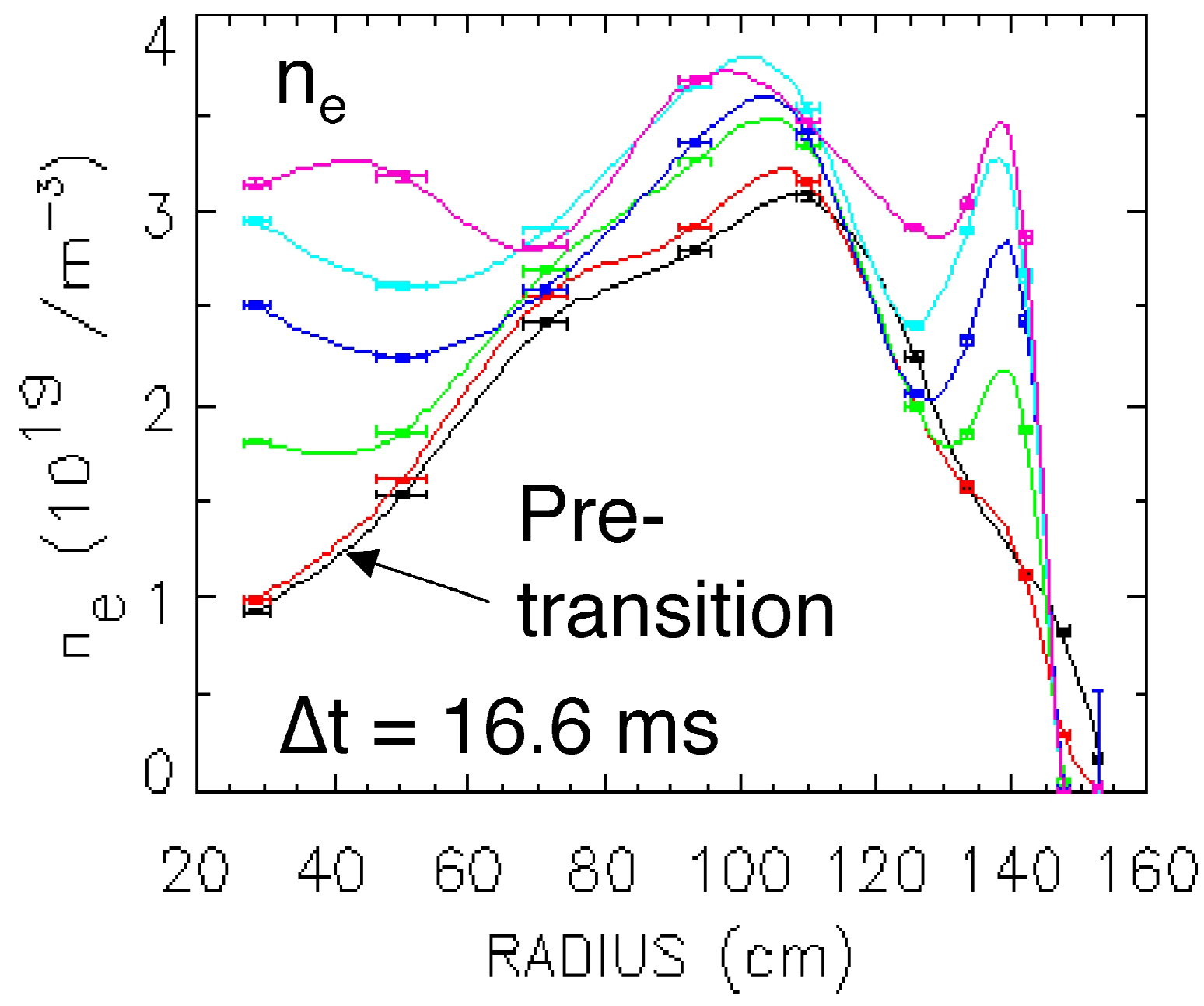


Figure 6 (a). Fast camera images of $\mathrm{He}^{0}$ emission near the scrapeoff layer before and after an $\mathrm{H}-$ to L- back transition in a 1.0 MA, $0.45 \mathrm{~T}$ plasma. The fluctuations in the light intensity result from plasma density fluctuations. A flux surface in the core runs from the lower left to the upper right of each image. (b). Time series of the intensity fluctuations at the two discrete points A and B. The expanded view illustrates that the turbulent activity returns in less than 20 microseconds, which is comparable to the expected turbulent eddy turnover time. (c). Quadrature reflectometry measurements of the edge turbulence density fluctuation amplitudes in the scrapeoff for the same discharge.

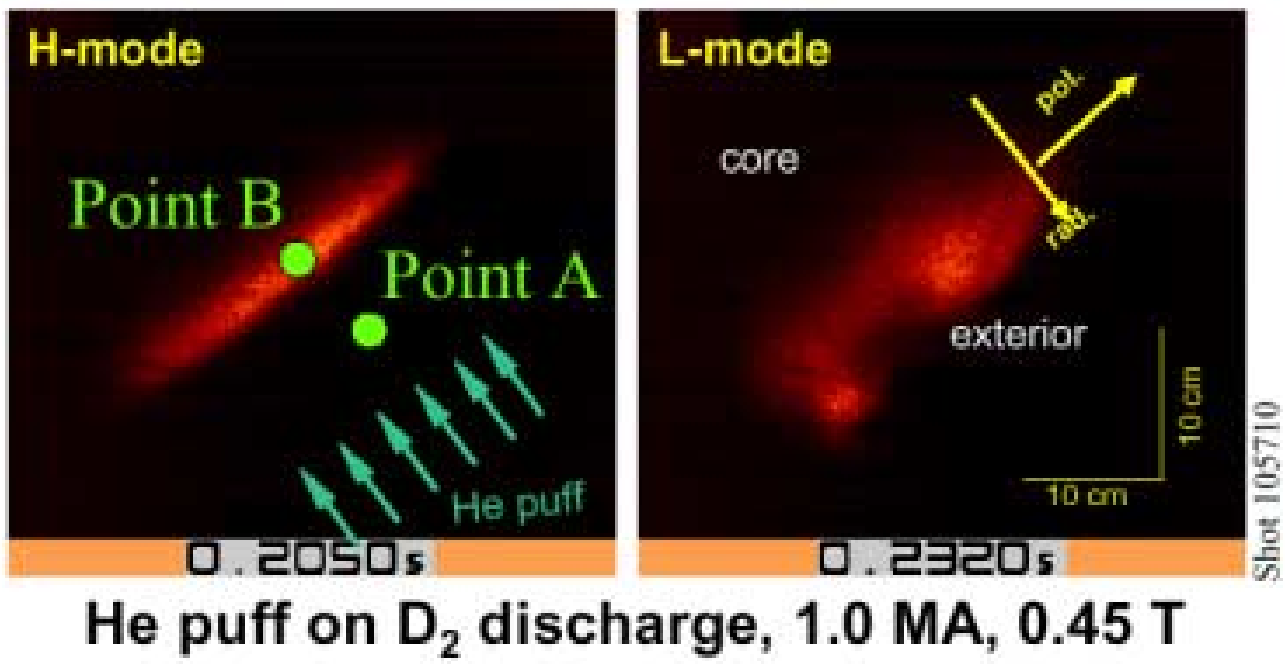

$6 a$.
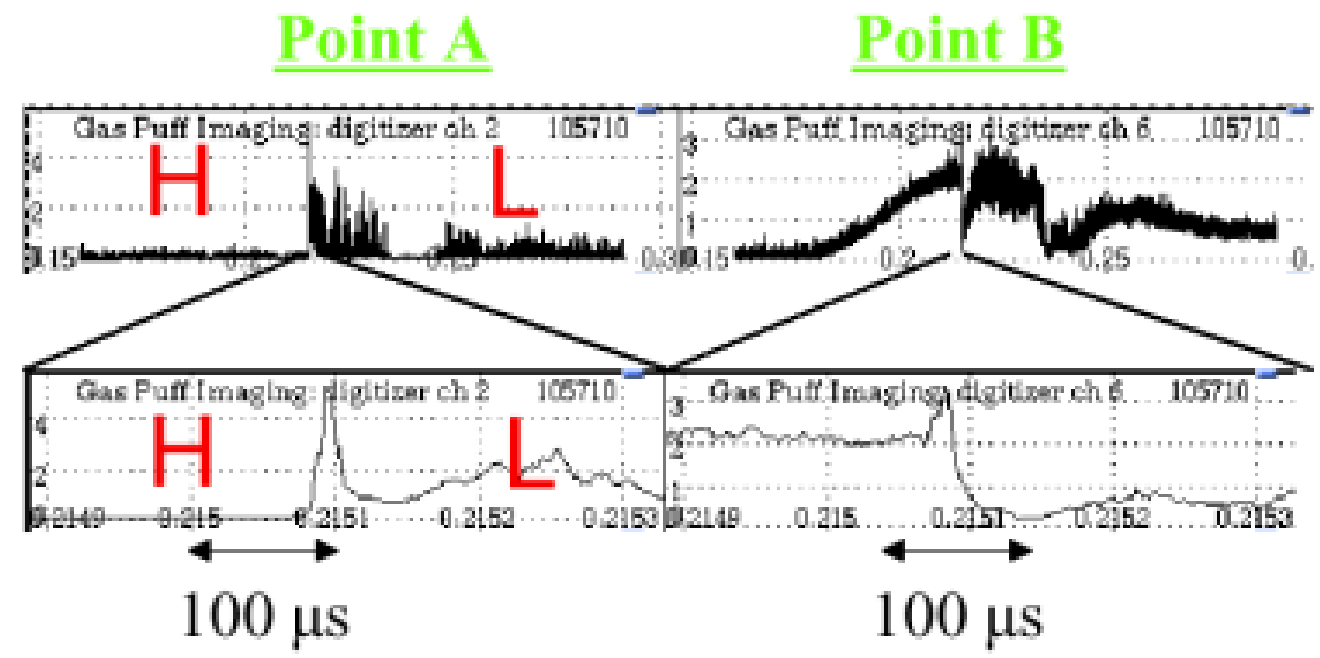

$6 b$. 
Synakowski et al. 


\section{External Distribution}

Plasma Research Laboratory, Australian National University, Australia

Professor I.R. J ones, Flinders University, Australia

Professor J oão Canalle, Instituto de Fisica DEQ/IF - UERJ , Brazil

Mr. Gerson O. Ludwig, Instituto Nacional de Pesquisas, Brazil

Dr. P.H. Sakanaka, Instituto Fisica, Brazil

The Librarian, Culham Laboratory, England

Library, R61, Rutherford Appleton Laboratory, England

Mrs. S.A. Hutchinson, JET Library, England

Professor M.N. Bussac, Ecole Polytechnique, France

Librarian, Max-Planck-Institut für Plasmaphysik, Germany

J olan Moldvai, Reports Library, MTA KFKI-ATKI, Hungary

Dr. P. Kaw, Institute for Plasma Research, India

Ms. P.J . Pathak, Librarian, Insitute for Plasma Research, India

Ms. Clelia De Palo, Associazione EURATOM-ENEA, I taly

Dr. G. Grosso, Instituto di Fisica del Plasma, Italy

Librarian, Naka Fusion Research Establishment, J AERI, J apan

Library, Plasma Physics Laboratory, Kyoto University, J apan

Research Information Center, National Institute for Fusion Science, J apan

Dr. O. Mitarai, Kyushu Tokai University, J apan

Library, Academia Sinica, Institute of Plasma Physics, People's Republic of China

Shih-Tung Tsai, Institute of Physics, Chinese Academy of Sciences, People's Republic of China

Dr. S. Mirnov, TRINITI, Troitsk, Russian Federation, Russia

Dr. V.S. Strelkov, Kurchatov Institute, Russian Federation, Russia

Professor Peter Lukac, Katedra Fyziky Plazmy MFF UK, Mlynska dolina F-2, Komenskeho Univerzita, SK-842 15 Bratislava, Slovakia

Dr. G.S. Lee, Korea Basic Science Institute, South Korea

Mr. Dennis Bruggink, Fusion Library, University of Wisconsin, USA

Institute for Plasma Research, University of Maryland, USA

Librarian, Fusion Energy Division, Oak Ridge National Laboratory, USA

Librarian, Institute of Fusion Studies, University of Texas, USA

Librarian, Magnetic Fusion Program, Lawrence Livermore National Laboratory, USA

Library, General Atomics, USA

Plasma Physics Group, Fusion Energy Research Program, University of California at San Diego, USA

Plasma Physics Library, Columbia University, USA

Alkesh Punjabi, Center for Fusion Research and Training, Hampton University, USA

Dr. W.M. Stacey, Fusion Research Center, Georgia Institute of Technology, USA

Dr. J ohn Willis, U.S. Department of Energy, Office of Fusion Energy Sciences, USA

Mr. Paul H. Wright, Indianapolis, Indiana, USA 
The Princeton Plasma Physics Laboratory is operated by Princeton University under contract with the U.S. Department of Energy.

\author{
Information Services \\ Princeton Plasma Physics Laboratory \\ P.O. Box 451 \\ Princeton, NJ 08543
}

Phone: 609-243-2750

Fax: 609-243-2751

e-mail: pppl_info@pppl.gov

Internet Address: http://www.pppl.gov 